Uday D. Bagale, Shirish H. Sonawane*, Bharat A. Bhanvase, Ravindra D. Kulkarni and Parag R. Gogate

\title{
Green synthesis of nanocapsules for self-healing anticorrosion coating using ultrasound-assisted approach
}

DOI 10.1515/gps-2016-0160

Received September 19, 2016; accepted March 22, 2017; previously published online June 3, 2017

\begin{abstract}
The present work deals with the production of nanocapsules containing a natural corrosion inhibition component. Azadirachta indica was encapsulated in ureaformaldehyde polymeric shell using ultrasound-assisted and conventional approaches of in situ polymerization. Subsequently nanocapsules were incorporated into clear epoxy polyamide to develop the green self-healing corrosion inhibition coating. The actual performance of the coating was evaluated based on the studies involving the repair of the crack of high solid surface coating. Corrosion inhibition of the healed area has been evaluated using the electrochemical impedance spectroscopy and immersion test based on the use of standard epoxy coating. The obtained results confirmed better corrosion protection in terms of the electrochemical impendence spectroscopy data and Tafel plot. It was found that current density decreases from $0.0011 \mathrm{~A} / \mathrm{cm}^{2}$ (for standard epoxy coating) to $5.22 \mathrm{E}^{-7} \mathrm{~A} / \mathrm{cm}^{2}$ as $4 \mathrm{wt} \%$ nanocapsules incorporated in coating.
\end{abstract}

Keywords: Azadirachta indica; electrochemical impendence spectroscopy (EIS); in situ polymerization; self-healing coating; ultrasound.

\footnotetext{
*Corresponding author: Shirish H. Sonawane, Department of Chemical Engineering, National Institute of Technology, Warangal 506004, India, e-mail: shirishsonawane09@gmail.com Uday D. Bagale: Department of Chemical Engineering, National Institute of Technology, Warangal 506004, India Bharat A. Bhanvase: Department of Chemical Engineering, Laxminarayan Institute of Technology, Rashtrasant Tukadoji Maharaj Nagpur University, Nagpur 440033, India Ravindra D. Kulkarni: University Institute of Chemical Technology, North Maharashtra University, Jalgaon 425001, India

Parag R. Gogate: Chemical Engineering Department, Institute of Chemical Technology, Mumbai 400019, India
}

\section{Introduction}

Interest in developing smart polymer coating, which either gives adequate corrosion inhibition or quick healing based on the use of natural materials has significantly increased in recent years and is considered as a green processing approach. One of the important examples of smarter coatings is the self-healing coating [1] where the self-healing agent is dispersed in the polymer resin matrix and the responsive release to a crack in the coating can lead to effective healing of the coating. Using natural materials as healing agents can be considered as mimicking the nature and these coatings should have the ability to heal themselves when subjected to mechanical or thermal damage recovering the initial functionalities in the absence of any external influences or corrective actions [2,3]. The self-healing coating provides advantages over conventional coating in terms of the self-responsive healing process, better barrier protection over the substrate, preserving the esthetic properties of coatings, and recovery of the mechanical properties of the coatings [4]. Such green coatings have significant applications as a protective coating has a positive impact on the substrate and also gives the required corrosion protection [5]. Till date, several approaches have been used for the fabrication of the self-healing coating with application to protect a metallic surface [4]. Different types of organic coatings have been reported to be effective in protecting metal surfaces based on corrosion inhibitors [6-8], cathodic protection [9], and barrier coatings [10-12]. The self-healing coating is important, especially in the case of microscale cracks as it is very difficult to repair the cracks which are at the microlevel with external interventions and hence, the development of smart functional coatings is of great importance. To the best of our knowledge, White et al. [13] was the first to report the development of self-healing coating based on the intrinsic system.

In this work, dicyclopentadiene (DCPD) was used as a healing agent encapsulated in urea-formaldehyde (UF) microcapsules and for the self-repairing function, DCPD was polymerized with the help of Grubbs catalyst as an 
activator. It was reported that during the application, the complete process does not require any external trigger for repairing, hence the coatings were described as "selfhealing." The process of obtaining self-healing coatings involves obtaining the microcapsules first and then subsequently embedding it inside the polymer matrix. Different methodologies are available to obtain the corrosion inhibitor containing nanocontainers [14-16]. Brown et al. [17] reported in situ polymerization approach for the encapsulation process based on obtaining oil-water emulsion. In this approach, UF was used as the shell material and different healing material was used as the core. Smart coatings based on the use of different healing agents encapsulated in polymeric microcapsule (i.e., UF, phenol-formaldehyde, and melamine-formaldehyde shell) have been reported in the literature [17]. Zhao et al. [18] reported the use of epoxy resin as a core and amine as an activator for the polymerization of epoxy resin for subsequent application as selfhealing coating. Sauvant-Moynot et al. [19] reported the fabrication of water-soluble and self-curable epoxy adduct with application as self-healing corrosion coating. Huang and Yang [20] reported the synthesis of self-healing anticorrosion coating based on the use of fluorotype silane as a core material in the UF polymeric shell. Most of the healing agents reported in the literature require the addition of catalyst for the polymerization of monomer. Use of the polymerizable material without catalyst is highly desirable for self-repairing material with an objective of reducing the overall cost. Nesterova et al. [21] developed the self-healing methodology based on drying oil having a composition of an unsaturated long chain of fatty acid which has the ability to react with oxygen from air to polymerize film for repairing the crack and protecting the surface from corrosion. Samadzadeh et al. [22] also reported a similar system based on the use of tung oil as a healant material for selfhealing and corrosion protection. Isophorone diisocyanate as a healing agent has also been reported [23] with modifications using oxygen plasma to produce a functional group on core material [24]. Recently, many a catalyst-free green healing materials have been reported for fabrication of the self-healing coating [25-28]. It was found that materials that are used for self-healing ability have some drawbacks. They are expensive and not usable for the production of microcapsules. Also, there is a problem of stability in dispersion in a resin matrix with a larger particle of microcapsules.

In the present work, use of sonication for the improved synthesis of nanocapsules using green corrosion inhibitor species (Azadirachta indica) derived from neem seed oil has been reported for the first time. As reported in the literature, the neem oil ( $A$. indica) is water insoluble and electrochemically active in nature. It has high concentration of alkaloids and fatty acid compounds were present in their structure. It also contains nitrogen and oxygen group in the backbone structure of neem oil which promotes the corrosion inhibition properties in the corrosive environment [29-31]. Use of sonication during green nanomaterial synthesis is expected to play a vital role with controlled morphology as reported in the literature [32-34]. They reported that the formation, growth, and collapse of a bubble in the aqueous phase arises because of the chemical and physical effects of ultrasound irradiation. These effects resulted in the formation of smaller size nanoparticles. Ultrasonic irradiations also prevent the agglomeration of the particles, which improve the dispersion ability of the coatings formulation $[29,30]$. Considering these aspects, $A$. indica (neem oil) has been used in the present work as a greener corrosion inhibition agent and was encapsulated in a polymeric shell made of UF. The corrosion inhibition performance of nanocapsules in the coating was evaluated using electrochemical spectroscopy and salt immersion test.

\section{Materials and methods}

\subsection{Materials}

Urea, formaldehyde, ammonium chloride, resorcinol, and polyvinyl alcohol (PVA) were obtained from Sigma-Aldrich as AR grade chemicals and used as received from the supplier without any further purification. Industrial epoxy resin, hardener, and reactive diluents were obtained from M/s Aditya Birla Ltd. Mumbai (India) whereas neem seed oil (commercial grade) was obtained from Neemko oil industries, India. Demineralized water was used for all the experiments. All reagent mention in materials were obtained from Sigma-Aldrich, Mumbai, India.

\subsection{Synthesis of nanocapsules by conventional and ultrasound method}

As reported in the literature [35] nanocapsules were prepared by in situ oil-in-water emulsion polymerization. The modified procedure for using conventional and ultrasound methods is as follows: ultrasound-assisted synthesis of nanocapsules was performed using probe sonicator. Initially, a surfactant solution was prepared using $35 \mathrm{ml}$ of distilled water, $0.3 \mathrm{~g}$ Span80, and $30 \mathrm{ml}$ 5\% PVA solution. Subsequently, $2.5 \mathrm{~g}$ urea, $0.21 \mathrm{~g}$ resorcinol, and $0.21 \mathrm{~g}$ ammonium chloride were added to this prepared solution. The $\mathrm{pH}$ of the solution was then adjusted to 3.5 by addition of hydrochloric acid for further reaction. The corrosion inhibitor, i.e., A. indica was added slowly to form an emulsion and allowed to stabilize under the action of ultrasound. After stabilization, $5 \mathrm{~g}$ of $37 \%$ aqueous solution of formaldehyde was added to maintain the molar ratio of urea and formaldehyde as 1:2. The reaction mixture was sonicated at $20 \mathrm{KHz}$ with a power of $120 \mathrm{~W}$ for $40 \mathrm{~min}$ and then the reaction mixture was heated to $50^{\circ} \mathrm{C}$ 
for $2 \mathrm{~h}$. Finally, the emulsion was cooled to room temperature and then vacuum filtration was used to yield the nanosize capsules. Subsequently the obtained capsules were washed with water and xylene to remove the suspended oil and dried at room temperature $\left(30^{\circ} \mathrm{C}\right)$. Whereas same concentration of all the same raw material based capsules was prepared using conventional method at $200 \mathrm{rpm}$ for $4 \mathrm{~h}$ reaction time at $60^{\circ} \mathrm{C}$.

\subsection{Characterization of nanocapsules}

Field emission scanning electron microscope (Hitachi S 4800 FESEM) was used to observe the external surface morphology of the synthesized nanocapsules. Samples were coated with $1.4 \mathrm{~nm}$ thick platinum using a cressington sputter coater before each FESEM analysis which was performed at an electron acceleration over $5-15 \mathrm{kV}$ generally recommended for imaging purposes. For the analysis of the capsule size and its distribution, particle size analyzer obtained from Malvern Instruments, UK was used. Thermogravimetric analysis (TGA) of the nanocapsules was also performed using Perkin Elmer TGA instrument in nitrogen environment at a heating rate of $10^{\circ} \mathrm{C} / \mathrm{min}$ over a temperature range of $30^{\circ} \mathrm{C}-800^{\circ} \mathrm{C}$. Differential scanning calorimeter (Perkin Elmer DSC: heating rate $10^{\circ} \mathrm{C} / \mathrm{min}$ over the temperature range of $30^{\circ} \mathrm{C}-800^{\circ} \mathrm{C}$ ) was also used to understand the thermal behaviour of nanocapsules. Functional group identification of nanocapsules was performed in a SHIMADZU FTIR- 8400 using the pellets obtained by pressing mixtures containing approximately $1 \mathrm{mg}$ of sample and $99 \mathrm{mg}$ of $\mathrm{KBr}$. Each spectrum was obtained in transmission mode, with a resolution of $2 \mathrm{~cm}^{-1}$ over the region of $4000-400 \mathrm{~cm}^{-1}$.

\subsection{Gooch crucible method for oil content analysis}

The core material ( $A$. indica) content in nanocapsules was analyzed using Gooch crucible method based on the weight loss measurements. The prepared nanocapsules (known quantity $W_{\mathrm{i}}$ ) were transferred to a dry Gooch crucible and xylene as an extract solvent for neem oil was added. In this method an extraction chamber was placed above the flask containing xylene and below the condenser. The flask was heated at $50^{\circ} \mathrm{C}$ to evaporate the solvent and move up to the extraction chamber containing the sample. At the completion of the process, the flask containing the xylene and oil was removed. At the end of extraction after closing the stopcock between the extraction chamber and the funnel which allows the recovery of some amount of the solvent. The obtained nanocapsules residue in the crucible was kept in an oven for drying and then the weight of the final dry product $\left(W_{\mathrm{f}}\right)$ was measured. The core content of the synthesized nanocapsules has been calculated using the following formula:

$$
\text { Core content }(\%)=\frac{W_{\mathrm{i}}-W_{\mathrm{f}}}{W_{\mathrm{i}}} \times 100
$$

where $W_{\mathrm{i}}$ is the initial weight of the product and $W_{\mathrm{f}}$ is the final weight of the product.

\subsection{Surface preparation for coating substrate}

The substrate surface preparation is an important step for the effective coating application as the surface preparation provides necessary interface for better adhesion characteristics. It not only improves the protective properties, but also enhances the esthetic appearance. For surface preparation, mild steel panel (size: $150 \mathrm{~mm} \times 70 \mathrm{~mm} \times 2 \mathrm{~mm}$ ) was first dipped into a soap solution to remove the oil lubricant and then the surface was cleaned by rubbing with emery paper.

\subsection{Formulation and performance evaluation of nanocapsules-based self-healing coating}

Nanocapsules were incorporated into an epoxy resin solution, which was prepared by diluting epoxy resin with low molecular weight $o$-xylene/n-butyl alcohol mixture. A polyamide (hardener) and a reactive diluent were also used in stoichiometric ratio for curing purpose. Nanocapsules were added into the solution of an epoxy resin and other constituents of coating (depending on the approach, details given in Table 1) were thoroughly mixed to form a homogeneous suspension using planetary ball mill. After homogenization, composition was mixed with required quantity of hardener and reactive diluents. Four compositions namely, clear epoxy polyamide coating and coating containing 2 and $4 \mathrm{wt} \%$ nanocapsules, respectively, were prepared as per the details mentioned in Table 1. The prepared mild steel panels were coated with freshly prepared coatings using a brush and the dry thickness was observed to be $120 \mu \mathrm{m}$.

A corrosion rate test was conducted in salt solution $(\mathrm{NaCl}$ : $5 \mathrm{wt} \%$ ) by placing the mild steel panel in porcelain dishes and coated samples were immersed in test media till observable deterioration occurred. Each sample was under media for $300 \mathrm{~h}$. The protective behavior of the corrosion inhibitor against the dissolution of mild steel was evaluated by calculating the corrosion rate $\left(V_{\mathrm{c}}\right)$ in $\mathrm{cm} /$ year for each sample using the expression given below [36].

$$
V_{C}=\frac{\Delta g}{A t d}
$$

where $\Delta g$ is the weight loss in grams for each sample, $A$ is the exposed area of the sample in $\mathrm{cm}^{2}, t$ is the time of exposure in years, and $d$ is the density of the metallic species in $\mathrm{g} / \mathrm{cm}^{3}$. The weight loss was measured after careful washing of the samples with water till the deposited corrosion products were removed, and finally, moisture was removed from the samples by drying the same at $60^{\circ} \mathrm{C}( \pm 1)$ in an oven till constant weight is obtained.

Table 1: Formulation for neem oil nanocapsules-based epoxy polyamide coating.

\begin{tabular}{lrrr}
\hline Material & $\begin{array}{r}\text { Epoxy polyamide } \\
\text { coating (part by } \\
\text { weight) }\end{array}$ & $\begin{array}{r}\text { Neem oil } \\
\text { nanocapsules based } \\
\text { epoxy polyamide } \\
\text { coating (wt\%) }\end{array}$ \\
\hline P-A & & & \\
Nanocapsules & - & 2 & 4 \\
Epoxy resin & 75 & 75 & 75 \\
Adhesion promoter & 0.3 & 0.3 & 0.3 \\
Wetting and dispersant & 0.2 & 0.2 & 0.2 \\
Butyl cellosolve & 02 & 02 & 02 \\
P-B & & & \\
Polyamide & 35 & 35 & 35 \\
Reactive diluent & 0.3 & 0.3 & 0.3 \\
\hline
\end{tabular}


For Tafel plot measurements for corrosion, all electrochemical measurements have been performed on computerized electrochemical analyzer (supplied by Autolab Instruments, Netherlands). An MS panel was used as the working electrode with a working area of $1 \mathrm{~cm}^{2}$ with a platinum sheet as the counter and a saturated calomel electrode as the reference electrode. Polarization measurements were taken after exposure to a $0.5 \mathrm{M} \mathrm{HCl}$ solution with the potential scanned between $-2 \mathrm{~V}$ and $+2 \mathrm{~V}$ at a rate of $2 \mathrm{mV} / \mathrm{s}$. All the electrochemical measurements were performed at room temperature $\left(25^{\circ} \mathrm{C}\right)$. Electrochemical impendence spectroscopy (EIS) analysis was also performed to monitor the behavior of the corrosion inhibitor in nanocapsules-based coating in terms of bode plot and Nyquist plot. The EIS data were collected for $2 \mathrm{~K}$ clear epoxy polyamide containing nanocapsules ( 2 and $4 \mathrm{wt} \%$ ) and scratch $2 \mathrm{~K}$ clear epoxy polyamide which was immersed in $3.5 \% \mathrm{NaCl}$ solution for 20 days. The EIS measurements were performed over the range of $10^{5}-10^{-2} \mathrm{~Hz}$ with the rms width of the sinusoidal voltage signal applied to the system as $10 \mathrm{mV}$.

\subsection{Characterization of self-healing process by immersion studies}

The healing property of the anticorrosive coating on MS panel having dimensions $150 \mathrm{~mm} \times 70 \mathrm{~mm} \times 2 \mathrm{~mm}$ was evaluated by immersing in salt solution. The coated panels with a dry thickness of 120 $\mu \mathrm{m}$ after curing for 7 days were scrubbed manually and immediately placed in $3.5 \mathrm{wt} \% \mathrm{NaCl}$ solutions at room temperature. The panel was kept immersed in the solution for a period of 20 days, during which images were recorded for monitoring the self-healing behaviors.

\section{Results and discussion}

As described by Brown et al. [17], the formation of UF capsule based on the in situ polymerization involved reaction between urea and formaldehyde to obtain methylol urea, which further condenses under acidic conditions to form polymeric shell. The encapsulation of the liquid core occurs simultaneously during the formation of the crosslinked polymer. During the initial stage of polymerization, both the reactant molecules are water soluble (i.e., rich in polar group). With further polymerization, the molecular weight of the obtained polymer increases gradually thereby reducing the presence of polar groups in the polymer. After some time, a bulky mass is obtained with the UF polymer becoming hydrophobic, which leads to the polymer being separated from water phase and getting accumulated on the already emulsified oil droplets (hydrophobic phase). The process further continues forming thin layer of shell over emulsified core. The schematic formation of nanocapsules based on the in situ polymerization has been shown in Figure 1. It is important to understand the selection of suitable loadings and the operating conditions has an important effect on the core material content as well as the morphology of the obtained nanocapsules.

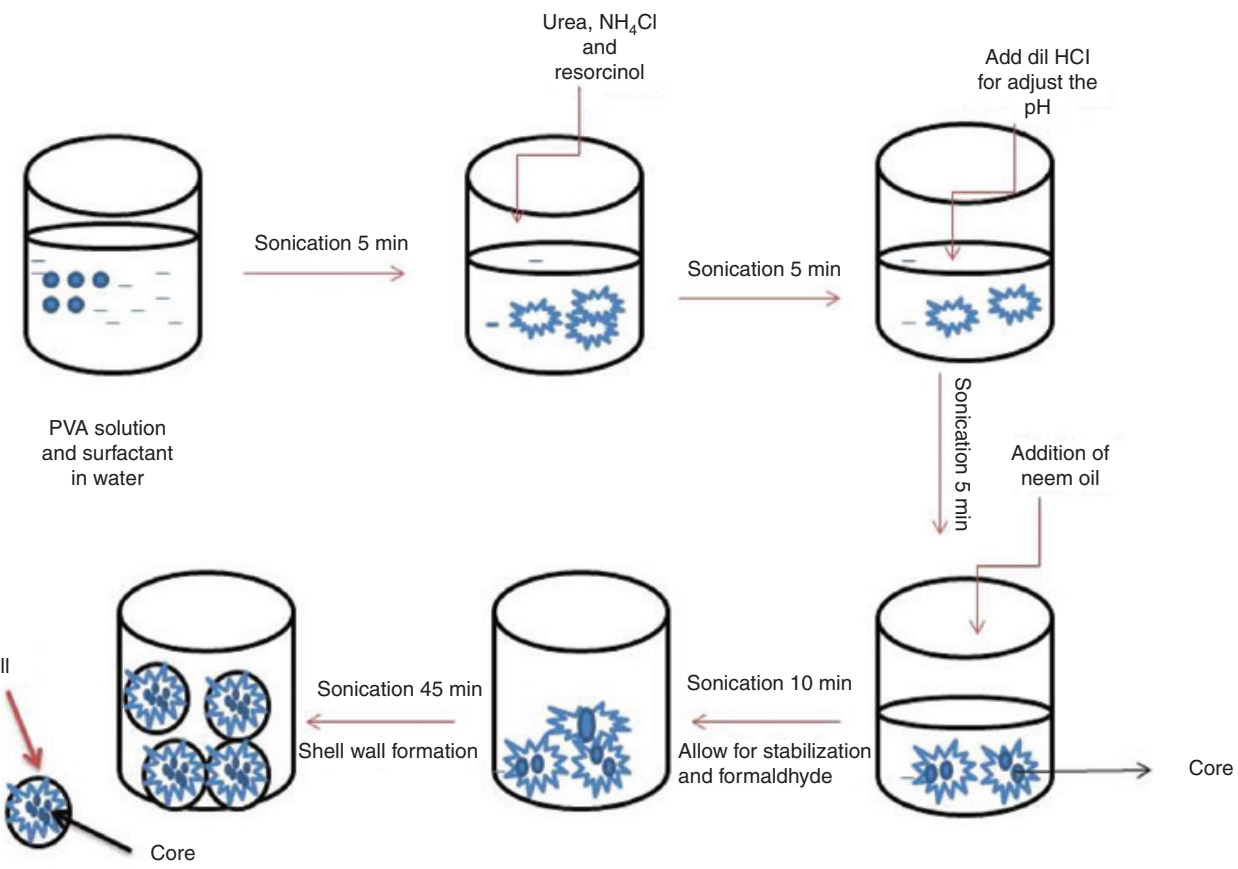

Figure 1: Schematic representation of the procedure for synthesis of neem oil nanocapsules. 


\subsection{Morphology and size analysis of capsules}

Resorcinol-based UF nanocapsules have been prepared using neem oil as core material with a constant agitation at $400 \mathrm{rpm}$ in the presence of ultrasonic probe of diameter $20 \mathrm{~mm}$ operating at a frequency of $20 \mathrm{kHz}$ with a power of $120 \mathrm{~W}$ and also using the conventional approach based on only agitation at $400 \mathrm{rpm}$. The obtained results for analysis of the obtained capsules using FESEM have been shown in Figure 2 for both the approaches. From the FESEM image, it is revealed that the core (A. indica) is completely encapsulated in the UF shell material. The capsules are having spherical shape with inner smooth surface and outer rough surface. In case of the ultrasound-assisted approach, the inner surface showed a thickness of 50$100 \mathrm{~nm}$ whereas the conventional approach showed a thickness of $5 \mu \mathrm{m}$. In case of the conventional approach, agglomerates were formed due to the sticky nature of the capsules, which was also attributed to insufficient surfactant concentration in the capsules. The agglomeration for the nanocapsules obtained using the conventional approaches is clearly revealed in the FESEM images. In the case of ultrasound-assisted approach, the degree of agglomeration was reduced and the mean particle size was lowered. Also, the obtained nanocapsules showed good degree of dispersion stability in aqueous phase in the case of ultrasound-assisted approach as reported in Figure 3. Using the particle size analyzer, it was confirmed that the ultrasound-based capsules had narrow particle
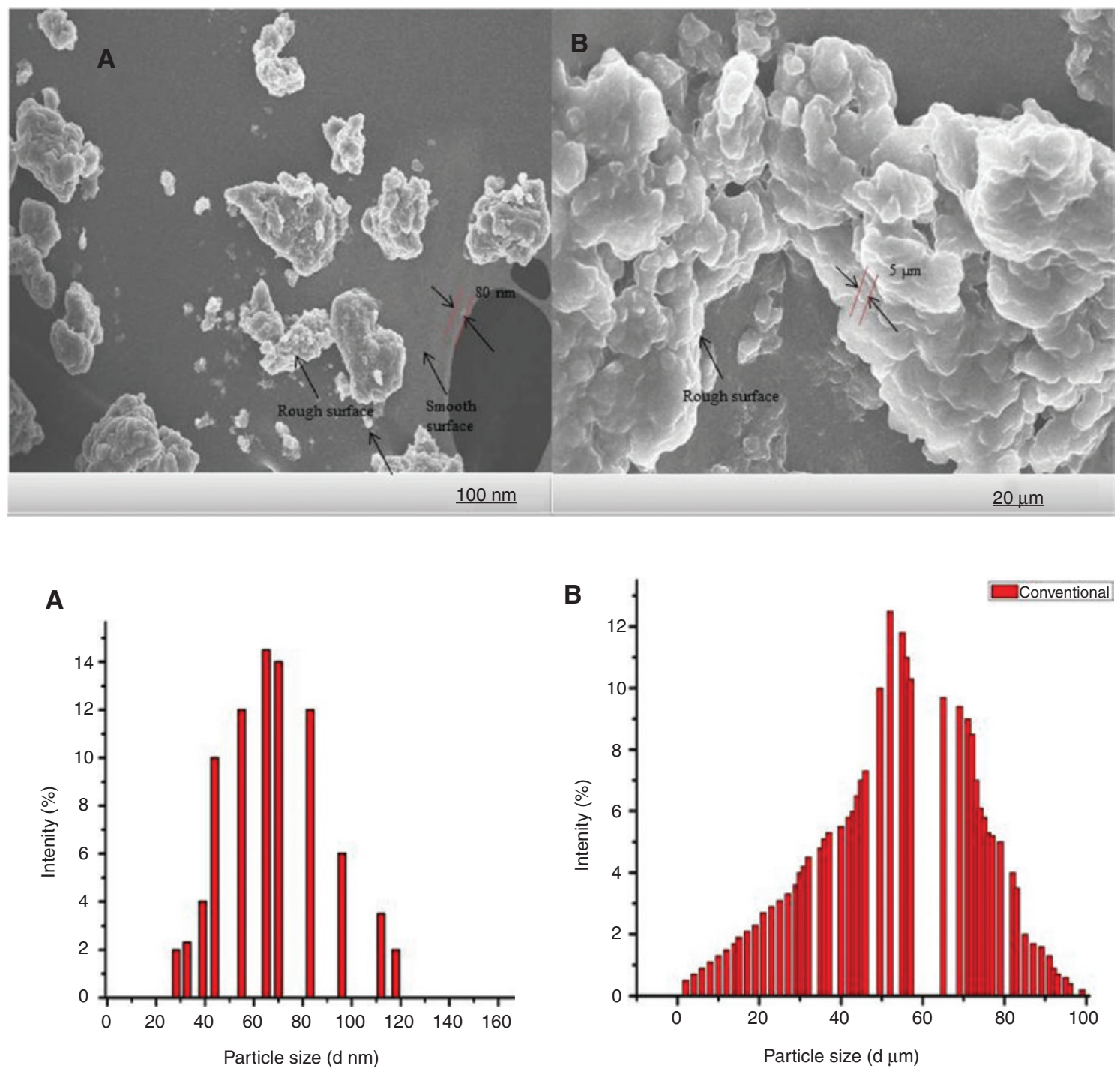

Figure 2: FESEM and particle size analysis of nanocapsules by (A) ultrasound method and (B) conventional method. 


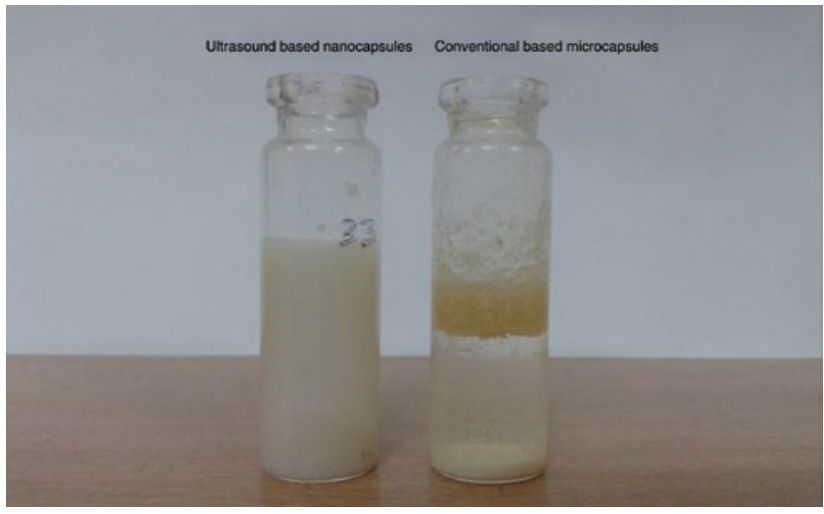

Figure 3: Actual photograph of stable nanocapsules emulsion.

size distribution with a mean size of $65 \mathrm{~nm}$ whereas for conventional method, broad particle size distribution was observed with a mean particle size of around 5-100 $\mu \mathrm{m}$. Better results for the ultrasound-assisted approach can be attributed to the intense turbulence and micro-scale mixing introduced by the cavitational effects induced by the passage of ultrasound $[29,31]$. The size of the nanocapsules is generally influenced by several factors including the geometry of mixing device, viscosity of reaction media, surfactant concentration, temperature, and sonication time. The FESEM and particle size data also confirmed that the use of sonication resulted in the smaller size of the nanocapsules [30].

\subsection{Evaluation of physical properties of nanocapsules}

Table 2 gives the physical property data for neem oil as core in the nanocapsules. It was observed that the sample of neem oil nanocapsules was slightly alkaline in nature with a $\mathrm{pH}$ of 8.1. The specific gravity of the nanocapsules was nearly the same as water. These two characteristics established that the prepared nanocapsules were stable and could be easily dispersed in water. Figure 3 gives the actual photograph of the stable nanocapsules-based emulsion for ultrasound-assisted approach. Capsules synthesized using conventional approach were found to be unstable (settling observed

Table 2: Physical evaluation of nanocapsules.

\begin{tabular}{lrr}
\hline Sample name & $\begin{array}{r}\text { Specific gravity } \\
\left(\mathrm{g} / \mathrm{cm}^{3}\right)\end{array}$ & $\begin{array}{r}\mathrm{pH}(1 \% \text { aqueous } \\
\text { dispersion) }\end{array}$ \\
\hline Neem oil nanocapsules & 0.9908 & 8.1 \\
\hline
\end{tabular}

which is shown in Figure 3) after 2 days of preparation whereas for the ultrasound-assisted approach, no such problem was observed. The observed results can be attributed to the insufficient amount and improper distribution of surfactant molecules in system which resulted in the formation of clusters as shown in FESEM image.

\subsection{Fourier transform infrared spectroscopic analysis of nanocapsules}

Figure 4 depicts the obtained data for the Fourier transform infrared spectroscopic analysis of the prepared nanocapsules using conventional and ultrasound methods and UF. It is observed that the IR spectra of both the methods and polymeric shell match with the reported similar characteristics for UF resin by Suryanarayana et al. [35]. The stretching vibration peaks at 1580,1631 , and $1440 \mathrm{~cm}^{-1}$ are attributed to the $\mathrm{N}-\mathrm{H}, \mathrm{C}=\mathrm{O}$, and $\mathrm{C}-\mathrm{H}$ bonding, respectively. The $\mathrm{C}-\mathrm{N}$ bond vibration is observed at a peak of $1246 \mathrm{~cm}^{-1}$ whereas the broad absorption peak of $\mathrm{O}-\mathrm{H}$ is observed at $3538-3310 \mathrm{~cm}^{-1}$. Also the carbonyl stretching, $\mathrm{CH}_{2}$ asymmetric deformation, and $\mathrm{C}-\mathrm{C}$ stretching were observed at an absorption band of 1733, 1453, and $1148 \mathrm{~cm}^{-1}$. In case of both the conventional and ultrasound approaches, the $\mathrm{CH}$ stretch of $\mathrm{C}=\mathrm{C}$ peak was observed at $3168 \mathrm{~cm}^{-1}$ and the amide $\mathrm{N}-\mathrm{H}$ stretch peak at $3722 \mathrm{~cm}^{-1}$ corresponding to the neem oil seed. The obtained spectrum characteristics confirmed successful encapsulation of the core material in UF shell.

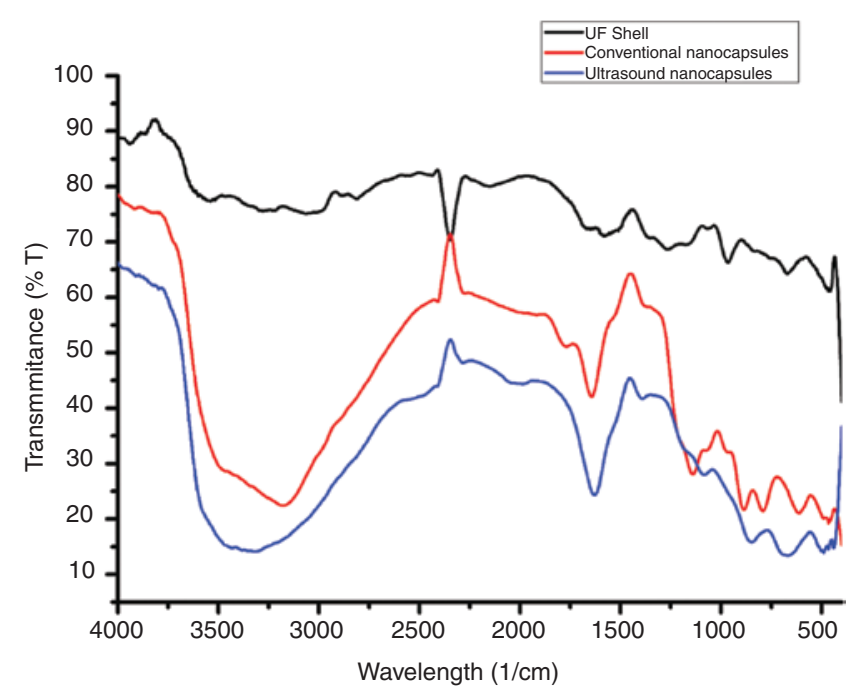

Figure 4: FTIR spectral analysis of (A) urea-formaldehyde, (B) nanocapsules conventional, and (C) nanocapsules ultrasound methods. 


\subsection{Thermal analysis of nanocapsules}

The thermal stability of the nanocapsules was evaluated using differential scanning calorimeter and TGA at a heating rate of $10^{\circ} \mathrm{C} / \mathrm{min}$ and the obtained data have been shown in Figures 5 and 6, respectively. TGA is one of the thermal analysis techniques used to measure the rate of change in the mass of sample as a function of temperature in controlled atmosphere. As per the data given in Figure 6, the nanocapsules prepared by the ultrasound and conventional methods showed overall weight loss of about $73.27 \%$ and $86.29 \%$ in the temperature range of $80^{\circ} \mathrm{C}-675^{\circ} \mathrm{C}$, respectively. For nanocapsules obtained using the ultrasound method, first weight loss (3.4\%) was

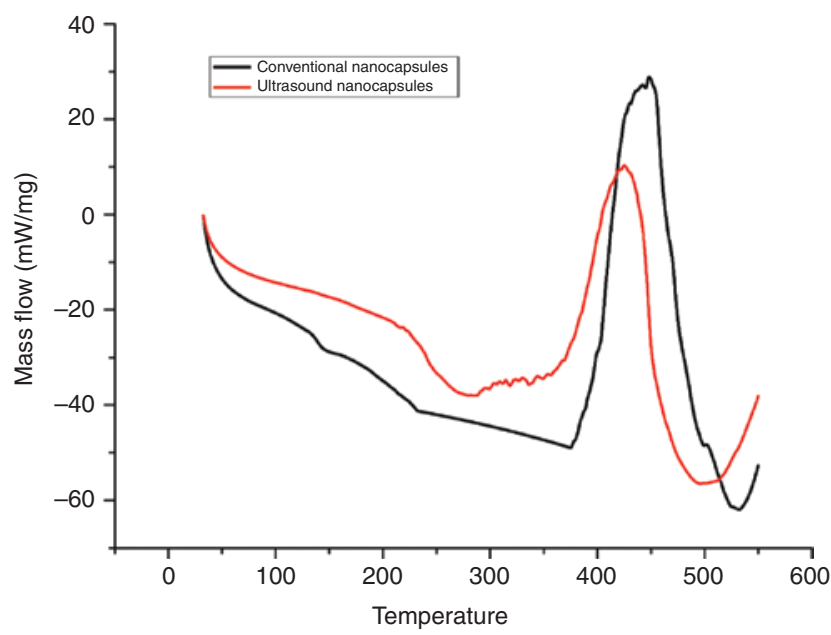

Figure 5: Differential scanning calorimetric analysis of nanocapsules (A) conventional method and (B) ultrasound method.

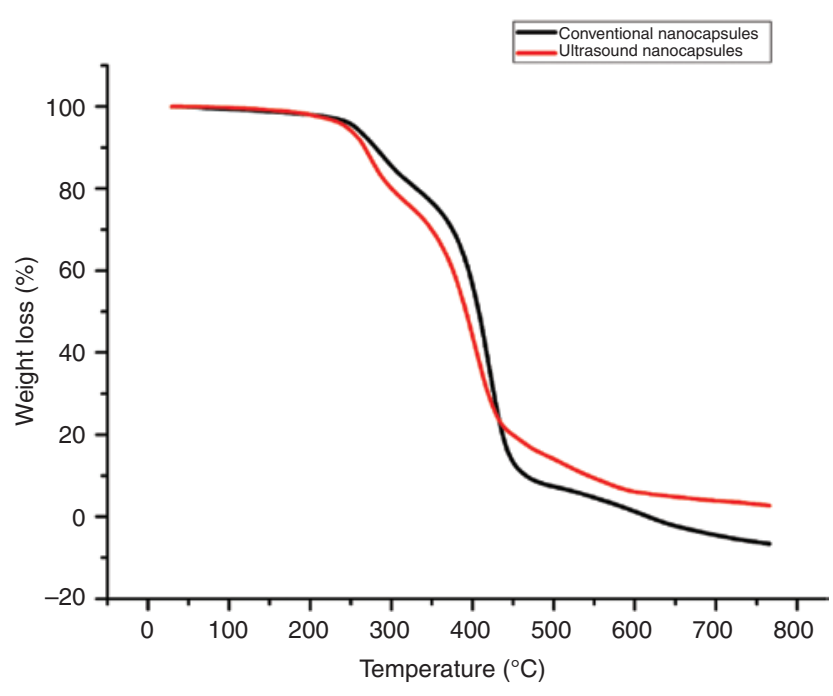

Figure 6: Thermogravimetric analysis of nanocapsules (A) conventional method (B) ultrasound method. observed in the range of $50^{\circ} \mathrm{C}-150^{\circ} \mathrm{C}$, which is attributed to the desorption of free and physically adsorbed water on nanocapsules [16]. The second weight loss (5.56\%) was observed in the range of $210^{\circ} \mathrm{C}-340^{\circ} \mathrm{C}$ attributed to the removal of $A$. indica and the acid contents. The total weight loss upto $650^{\circ} \mathrm{C}$ is observed to be $73.27 \%$ whereas in the case of nanocapsules obtained using conventional method the overall weight loss is more. Over the initial range of temperature, in the case of conventional based nanocapsules, weight loss observed is significantly higher which is attributed to the higher particle size of prepared nanocapsules. The particle size of the neem oil nanocapsules prepared by ultrasound method was significantly lesser than that obtained using the conventional approach and, therefore, it can be predicted that the weight loss in case of ultrasound method must be lower than the conventional method [37].

The differential scanning calorimetry (DSC) curves of the capsules obtained using the ultrasound-assisted and conventional approaches as depicted in Figure 5 show two endothermic and two exothermic peaks. The first endothermic peak is observed below $100^{\circ} \mathrm{C}$ which is attributed to the evaporation of water and free formaldehyde present in the nanocapsules solution. At temperatures between $250^{\circ} \mathrm{C}$ and $300^{\circ} \mathrm{C}$, second endothermic peak is observed due to the degradation of the shell. The two exothermic peaks are attributed to the core polymerization reaction occurring at $260^{\circ} \mathrm{C}$ and to the continuous reaction of oil occurring around $320^{\circ} \mathrm{C}-330^{\circ} \mathrm{C}$. The same observations were also observed in the TGA graphs. It was also established using the represented data that the thermal stability of the nanocapsules obtained using the ultrasound-assisted approach was better as compared to the nanocapsules obtained using the conventional method.

\subsection{Electrochemical characterization of nanocapsules-based epoxy polyamide coatings}

The presence of moisture and oxygen in the environment induces corrosion effects on the materials through the damage points on the coating-substrate interface. Repairing the damage or crack can thus provide a better resistance to corrosion. To understand the effect of $A$. indica as a corrosion inhibitor being incorporated as nanocapsules in epoxy polyamide coating, electrochemical corrosion analysis with weight loss measurement, Tafel plot, and EIS were performed. Figure 7 depicts the effect of loading of nanocapsules on the corrosion rate and it can be seen that the corrosion rate decreased with 


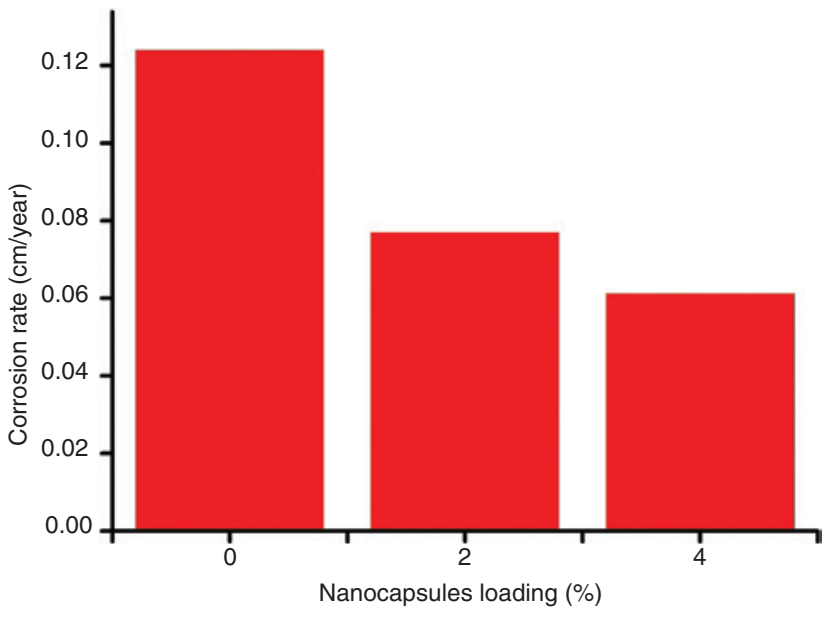

Figure 7: Effect of nanocapsules loading on corrosion rate after loading into epoxy polyamide coating.

the incorporation of nanocapsules in the clear epoxy polyamide coating. Loading of $2 \%$ by weight resulted in significant improvement in the anticorrosion property and further increase in the loading to $4 \%$ by weight resulted in marginal improvement. The actual corrosion rates for clear epoxy polyamide, coating with $2 \mathrm{wt} \%$ nanocapsules and coating with $4 \mathrm{wt} \%$ nanocapsules were observed to be $0.1239,0.077$, and $0.0612 \mathrm{~cm} /$ year, respectively. The results shown clearly indicate that corrosion rate substantially decreased (around 50\%) when nanocapsules (at $2 \mathrm{wt} \%$ loading) were incorporated into epoxy polyamide clear coating. Figure 8 shows the Tafel plot for bare metal and clear epoxy polyamide coating containing nanocapsules $(0-4 \mathrm{wt} \%)$. It can be observed that the corrosion current density decreased with an

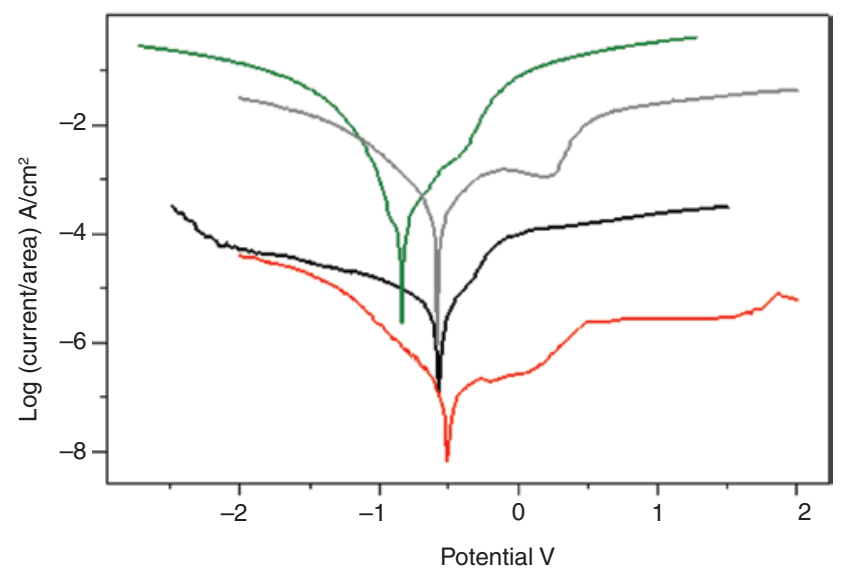

Figure 8: Tafel plots for the MS stripes coated with different coatings of nanocapsules in $0.5 \mathrm{M} \mathrm{HCl}$ solution (green: bare metal; grey: epoxy neat; black: $2 \%$ neem oil; and red: $4 \%$ neem oil). increase in the concentration of encapsulated $A$. indica based capsules in the epoxy polyamide clear coating. It was found that $I_{\text {corr }}$ value is $0.015 \mathrm{~A} / \mathrm{cm}^{2}$ for the bare metal which decreases to $0.0011 \mathrm{~A} / \mathrm{cm}^{2}$ (for clear epoxy polyamide coating) and to $3.15 \times 10^{-5} \mathrm{~A} / \mathrm{cm}^{2}$ when coating was applied with $2 \mathrm{wt} \%$ of encapsulated $A$. Indica as the core. The $I_{\text {corr }}$ value further decreased to $5.22 \times 10^{-7} \mathrm{~A} / \mathrm{cm}^{2}$ in the case of $4 \mathrm{wt} \%$ encapsulated $A$. Indica. The $E_{\text {corr }}$ values were also found to shift from negative to positive side confirming that corrosion inhibition increases with an increase in the loading of green corrosion inhibition agent. The observed trend can be attributed to the fact that $A$. indica forms a passivating layer on the surface of substrate which resists the coating from corrosion. This observation is also supported by the earlier corrosion rate data obtained by dip test method.

To understand the corrosion behavior of $A$. indica based nanocapsules containing clear epoxy polyamide coating, clear epoxy polyamide and scratch clear epoxy polyamide were applied on mild steel panel and were immersed in $3.5 \mathrm{wt} \% \mathrm{NaCl}$ solution for 20 days and the analysis was performed at different time intervals in terms of the impedance (Bode and Nyquist plot) of the coating. An equivalent circuit of epoxy polyamide clear coated and epoxy polyamide-nanocapsules-coated mild steel panels can be represented by the model as shown in Figure 9. This model is a representation of the polymer-coated metals $[38,39]$. The circuit consists of the solution resistance $\left(R_{\mathrm{s}}\right)$, coating resistance $\left(R_{\mathrm{c}}\right)$, and coating capacitance $\left(C_{C}\right)$. Figures $10 \mathrm{~A}-\mathrm{D}$ and 11 represent the Bode plot and Nyquist plot in terms of impendence. The data depicted in Figure 10A-D established that clear epoxy polyamide coating failed to inhibit the corrosion resulting in severe

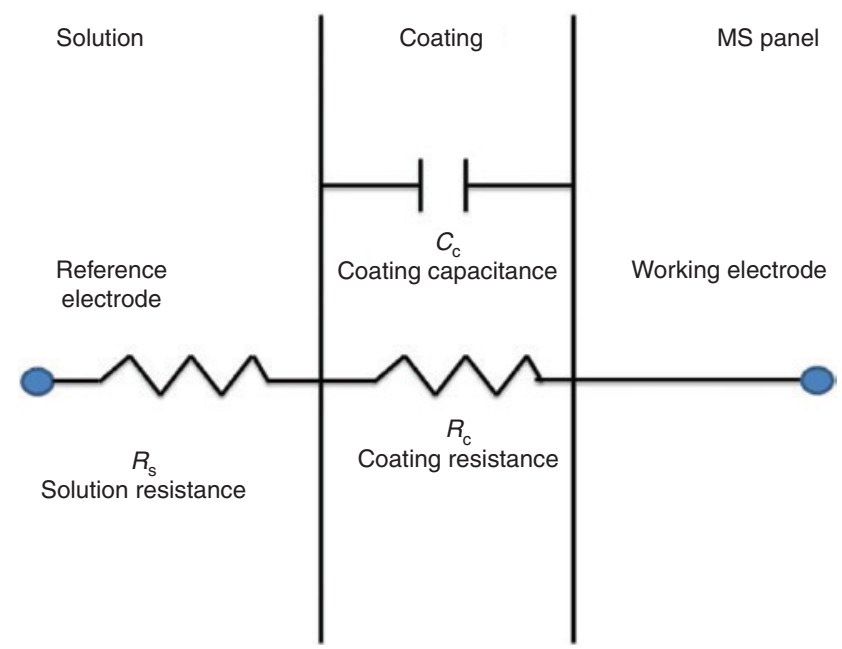

Figure 9: Equivalent circuit used for the modeling of the impendence curve. 

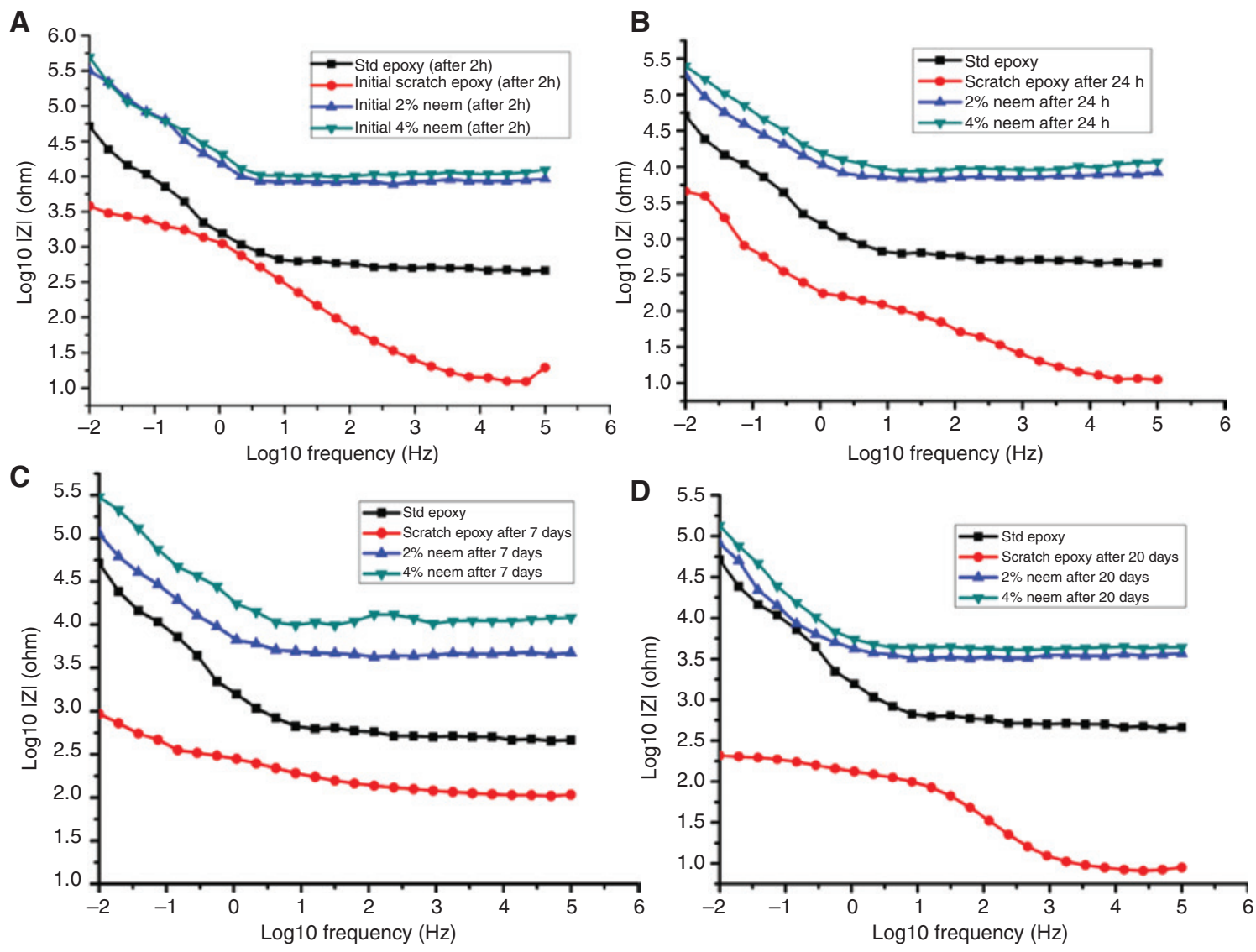

Figure 10: Bode plot for the EIS data for samples immersed in $3.5 \mathrm{wt} \% \mathrm{NaCl}$ aqueous solution. (A) After $2 \mathrm{~h}$, (B) after $24 \mathrm{~h}$, (C) after 7 days, and (D) after 20 days.
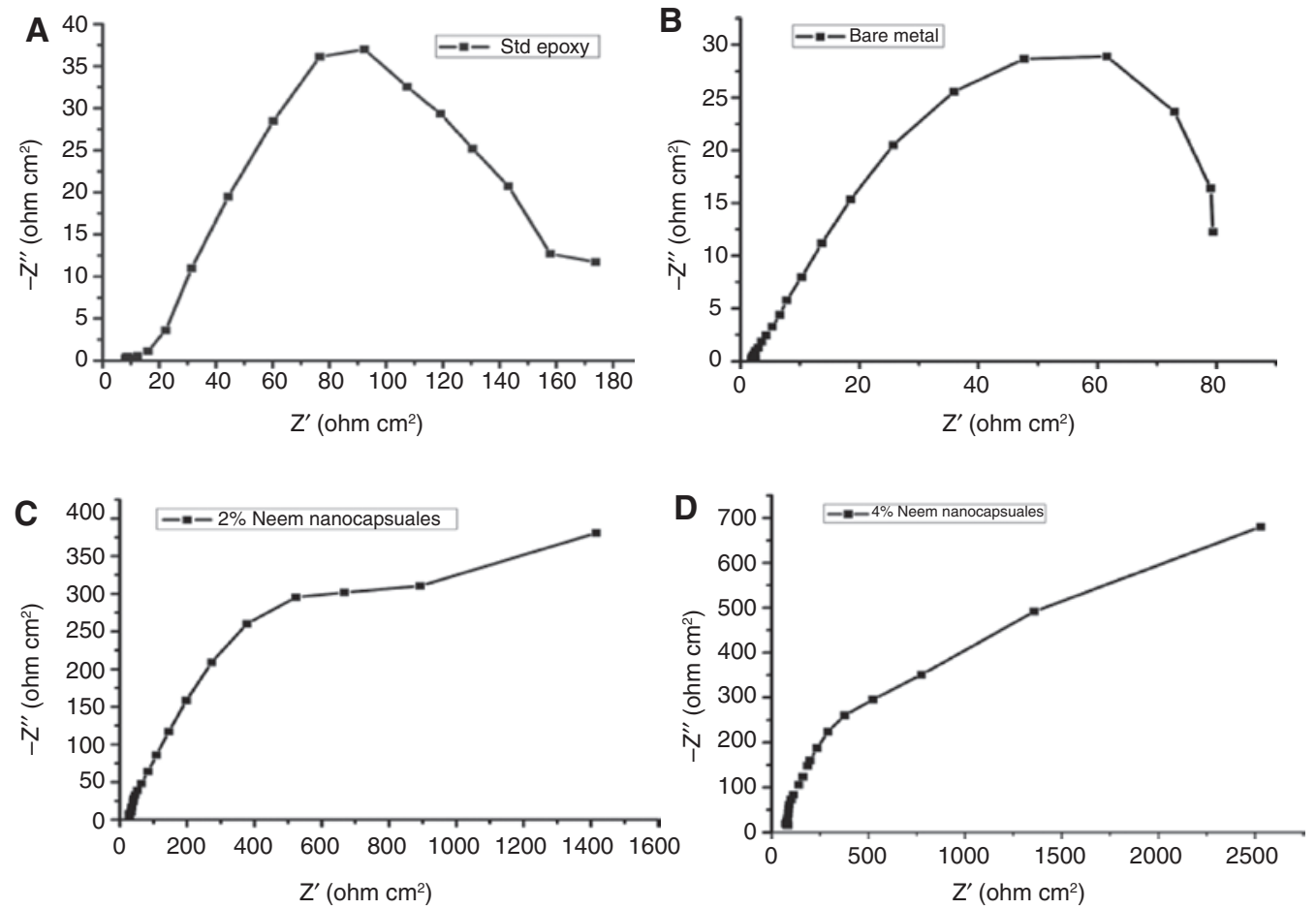

Figure 11: Nyquist plot for self-healing anticorrosion nanocomposite coating base nanocapsules.

(A) Standard Epoxy-polyamide coating; (B) bare metal, (C) 2\% neem nanocapsules based coating, and (D) 4\% neem nanocapsules based coating. 
damage after 20 days of immersion. Similar results were also observed for the unscratched clear epoxy polyamide clear coating demonstrating poor corrosion resistance. The impendence value for both these cases was observed to decrease to $2-3 \Omega$ which is similar to the reports of Szabo et al. [40]. On the other side, the application of green corrosion inhibitor $A$. indica based nanocapsules dispersed in clear epoxy polyamide coating provided much better corrosion protection and only marginal corrosion was observed even after 20 days of immersion. The impendence values for 2 and $4 \mathrm{wt} \%$ nanocapsules were 3.5 and 3.7 $\Omega$, respectively, which are better than that observed in the case of tung oil based self-healing [22]. It was also observed that the impedance values are higher and increase with an increase in the loading of nanocapsules in the epoxy resin which confirmed better anticorrosion performance. Analysis of the effect of loading of nanocapsules using different parameters as actual corrosion rate and other corrosion indicators (Tafel plot, Bode, and Nyquist plot) confirmed that $2 \mathrm{wt} \%$ loading gave best results and subsequent increase to $4 \mathrm{wt} \%$ loading resulted in marginal improvement in the corrosion inhibition characteristics.

Nyquist plot depicted in Figure 11 also indicates that the corrosion impedance was found to be increased with incorporation of $4 \mathrm{wt} \%$ nanocapsules in $2 \mathrm{~K}$ epoxy polyamide clear coats. The impedance in case of $2 \mathrm{~K}$ epoxy polyamide clear coatings applied on mild steel panels was observed to be $175 \Omega \mathrm{cm}^{2}$ which increased to $2500.20 \Omega \mathrm{cm}^{2}$ with the incorporation of $4 \mathrm{wt} \%$ nanocapsules in $2 \mathrm{~K}$ epoxy polyamide coat [39]. In the case of bare metal, the corrosion impedance was only $80 \Omega \mathrm{cm}^{2}$ which means very poor corrosion resistance. Thus, it was established that the coating containing $A$. indica based nanocapsules provides very strong level of corrosion inhibition to the underlying metal surface attributed to the presence of hetero atom of nitrogen. It is obvious that the mechanical properties of repaired area are not the same as the original epoxy structure, but the formation of a passive layer between oxygen and surface can increase the shell life of coating in terms of corrosion [35].

\subsection{Immersion study for self-healing process}

The easiest way to examine the corrosion is based on any physical changes that can be observed in the coated panel. The coated mild steel panels were immersed in salt solutions and the changes were monitored in the case of nanocapsules epoxy amide coated panel exposed to $5 \% \mathrm{NaCl}$ solution for 20 days. The obtained photographic images shown in Figure 12 confirmed that the uncoated panel shows corrosion on exposure to the salt

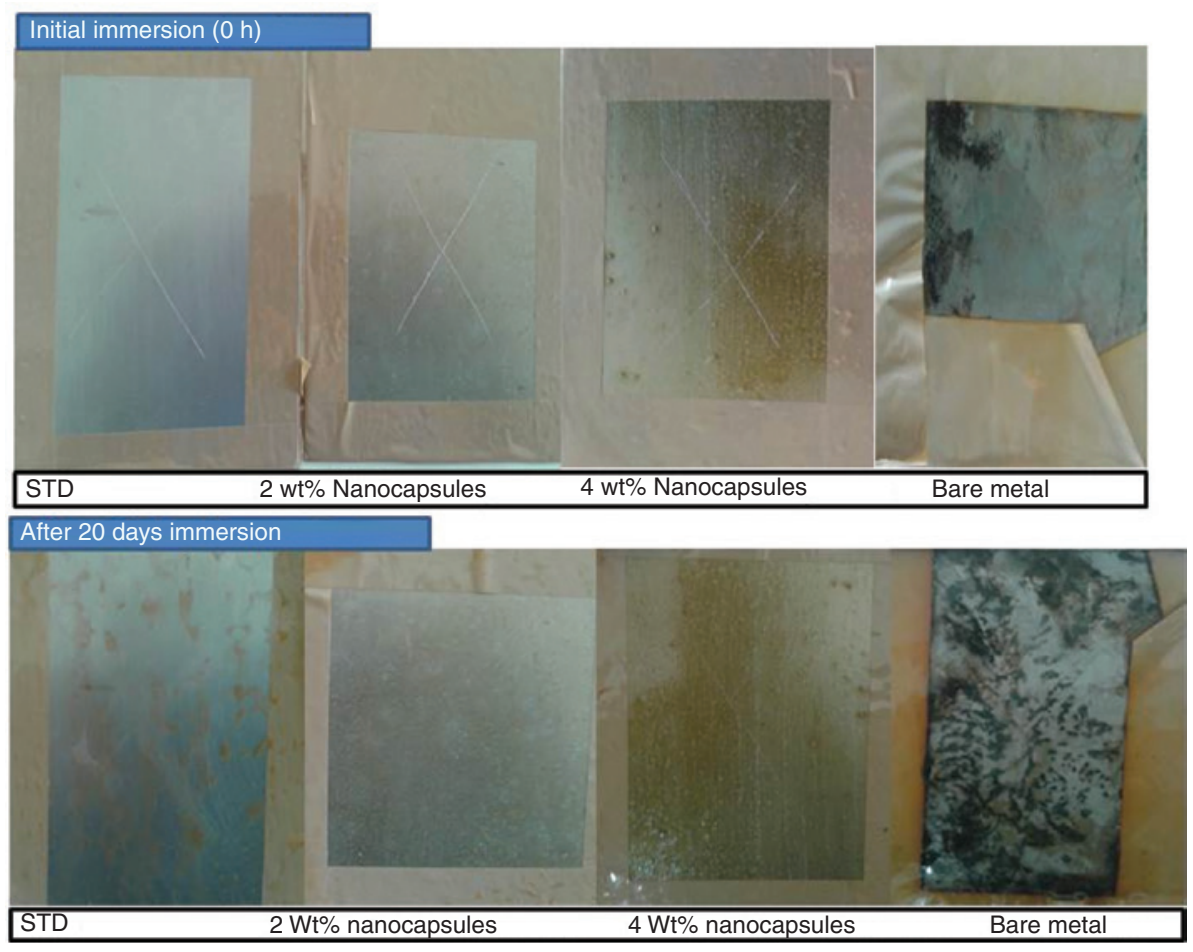

Figure 12: Immersion study of nanocapsules in $5 \% \mathrm{NaCl}$ solution for 20 days. 
solution, while nanocapsules epoxy amide coated panel shows corrosion resistance attributed mainly to the presence of nanocapsules as it also gives better healing properties which means that the core material is automatically healing the crack observed during the damage without the need of any external trigger. The use of $A$. indica based nanocapsules provides an external layer on the surface of the coated substrate displaying the corrosion protection function. The scratch on the clear epoxy coating substrate was observed to be severely corroded when the substrate was exposed to corrosive salt solution. Rule et al. [41] also reported that the healing performance was directly dependent on the amount of the available healing agent for release per unit scratchy area suggesting that smaller nanocapsules size, higher nanocapsules content, and thicker coating will provide better corrosion protection.

From the overall results of weight loss method, electrochemical (Tafel plot), immersion studies analysis, and EIS confirmed that the addition of nanocapsules containing $2 \mathrm{wt} \%$ of the core material in encapsulated form in the epoxy polyamide coating showed significant enhancement in the corrosion inhibition properties compared to clear epoxy polyamide coating and marginal improvement was observed for further increase in the loading to $4 \mathrm{wt} \%$.

\section{Conclusions}

The green processing approach of the development of corrosion inhibition coating using $A$. Indica as the core material encapsulated in polymeric shell (UF) has been reported in the present work. The formation of the encapsulated nanocapsules was successfully established using the FESEM analysis with uniform particle size distribution obtained in the case of ultrasoundassisted approach as compared to the conventional approach. The DSC and TGA results also confirmed the excellent thermal stability of coating obtained using the ultrasound-assisted approach. The corrosion inhibition by green coating was also successfully demonstrated using salt immersion test as well as the Tafel plot and EIS analysis. The better self-healing behavior and corrosion inhibition were demonstrated for the nanocapsulesloaded clear epoxy polyamide coating. Overall, this work successfully demonstrated the synthesis and application of nanocapsules-based polymeric shells for corrosion inhibition with better results as compared to the clear polymeric coatings.
Acknowledgments: The authors acknowledge DRDO (Government of India) for providing funding under grant number ERIP/ER/1206027/M/01/1539.

\section{References}

[1] Trask RS, Williams HR, Bond IP. Bioinspir. Biomim. 2007, 2, 1-9.

[2] Montemor MF. Surf. Coat. Technol. 2014, 258, 17-37.

[3] Riaz U, Nwaoha C, Ashraf SM. Prog. Org. Coat. 2014, 77, 743-756.

[4] Urban MW. Angew. Chem. Int. Ed. 2014, 53, 3775.

[5] Wei Z, Yang JH, Zhou J, Xu F, Zrinyi M, Dussault PH, Osada Y, Chen YM. Chem. Soc. Rev. 2014, 43, 8114-8131.

[6] Sayin K, Karkas D. Corros. Sci. 2013, 77, 37-45.

[7] Granizo N, Vega JM, de la Fuente D, Simancas J, Morcillo M. Prog. Org. Coat. 2012, 75, 147-161.

[8] Marathe RJ, Chaudhari AB, Hedaoo RK, Sohn D, Chaudhari VR, Gite VV. RSC Adv. 2015, 5, 15539-15546.

[9] Wang X, Wang C, Tang X, Guo Z. Int. J. Electrochem. Sci. 2014, 9, 8199-8210.

[10] Fayyad EM, Almaadeed MA, Jones A, Abdullah AM. Int. J. Electrochem. Sci. 2014, 9, 4989-5011.

[11] Mahmoudian YA, Basirun WJ. Prog. Org. Coat. 2012, 75, 301-308.

[12] Tian Z, Yu H, Wang L, Saleem M, Ren F, Ren P, Chen Y, Sun R, Sun Y, Huang L. RSC Adv. 2014, 4, 28195-28208.

[13] White SR, Sottos NR, Geubelle PH, Moore JS, Kessler MR, Sriram SR, Brown EN, Viswanathan S. NCBI 2001, 409, 794-797.

[14] Zheludkevich ML, Poznyak SK, Rodrigues LM, Raps D, Hack T, Dick LF. Corros. Sci. 2010, 52, 602-611.

[15] Tedim J, Poznyak SK, Kuznetsova A, Raps D, Hack T, Zheludkevich ML. ACS Appl. Mater. Interfaces 2010, 2, 1528-1535.

[16] Sonawane SH, Bhanvase BA, Jamali AA, Dubey SK, Kale SS, Pinjari DV, Pandit AB. Chem. Eng. J. 2012, 189-190, 464-472.

[17] Brown E, Kessler M, Sottos N. J. Microencapsul. 2003, 20, 719-730.

[18] Zhao Y, Zhang W, Liao L, Wang S, Li W. Appl. Surf. Sci. 2012, 258, 1915-1918.

[19] Sauvant-Moynot V, Gonzalez S, Kittel J. Prog. Org. Coat. 2008, 63, 307-315.

[20] Huang M, Yang J. J. Intell. Mater. Syst. Struct. 2014, 25, 98-106.

[21] Nesterova T, Dam-Johansen K, Pedersen LT, Kiil S. Prog. Org. Coat. 2012, 75, 309-318.

[22] Samadzadeh M, Boura SH, Peikari M, Ashra A, Kasiriha M. Prog. Org. Coat. 2011, 70, 383-387.

[23] Wang W, Xu L, Li X, Yang Y, An E. Corros. Sci. 2014, 80, $528-535$

[24] Wang W, Xu L, Li X, Lin Z, Yang Y, An E. J. Mater. Chem. A 2014, 2, 1914-1921.

[25] Tatiya PD, Hedaoo RK, Mahulikar PP, Gite VV. Ind. Eng. Chem. Res. 2013, 52, 1562-1570.

[26] Koh E, Kim NK, Shin J, Kim YW. RSC Adv. 2014, 4, 16214-16223. 
[27] Wu G, An J, Tang XZ, Xiang Y, Yang J. Adv. Funct. Mater. 2014, $24,6751-6761$.

[28] Li GL, Schenderlein M, Men Y, Mohwald H, Shchukin DG. Adv. Mater. Interfaces 2014, 1, 1300019-1300024.

[29] Sharma SK, Peter A, Obot IB. J. Anal. Sci. Technol. 2015, 6 , 26-41.

[30] Bhola SM, Alabbas FM, Bhola R, Spear JR, Mishra B, Olson DL, Kakpovbi AE. Eng. Failure Anal. 2014, 36, 92-103.

[31] Desai PS. Int. J. Eng. Res. 2015, 3, 8-23.

[32] Sonawane SH, Chaudhary P, Ambade S, Ghodke S. Ultrason. Sonochem. 2008, 15, 1033-1037.

[33] Sonawane SH, Chaudhari PL, Ghodke SA, Parande MG, Bhandari VM, Mishra S, Kulkarni RD. Ultrason. Sonochem. 2009, 16, 351-355.

[34] Sonawane SH, Teo BM, Brotchie A, Grieser F, Ashokkumar M. Ind. Eng. Chem. Res. 2010, 49, 2200-2220.

[35] Suryanarayanaa C, Chowdoji Rao K, Kumar D. Prog. Org. Coat. 2008, 63, 72-78.

[36] Bhanvase BA, Sonawane SH. Chem. Eng. J. 2010, 156, 177-183.

[37] Bhanvase BA, Pinjari DV, Gogate PR, Sonawane SH, Pandit AB. Chem. Eng. J. 2012, 181-182, 770-778.

[38] Beaunier L, Epelboin I, Lestrade JC, Takenouti H. Surf. Technol. 1976, 4, 237-254.

[39] Hamdy AS, El-Shenawy E, El-Bitar. Int. J. Electrochem. Sci. 2006, 1, 171-180.

[40] Szabo T, Telegdi J, Nyikos L. Prog. Org. Coat. 2015, 84, 136-142.

[41] Rule J, Sottos N, White S. Polymer 2007, 48, 3520-3529.

\section{Bionotes}

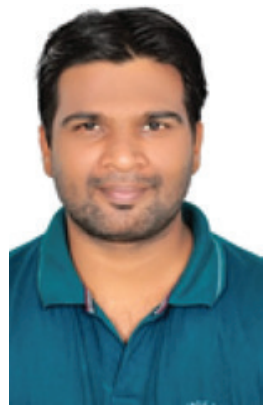

Uday D. Bagale

Uday D. Bagale received his BTech and MTech degrees in paint technology from University Institute of Chemical Technolgy, NMU Jalgaon, India in 2010 and 2014, respectively. He is currently working as a research scholar at the National Institute of Technology, Warangal. He has filed an Indian patent on improved self-healing corrosion inhibition coating based on nanocapsules using sonochemicals. His research areas are surface and coating technology, corrosion protection coating, emulsion and resin, and nanotechnology.

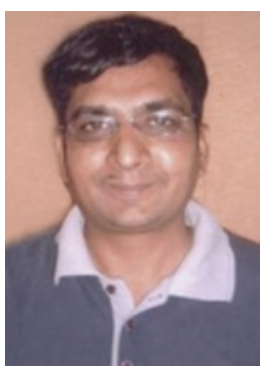

Shirish H. Sonawane

Shirish $\mathrm{H}$. Sonawane is currently working as an associate professor at the Chemical Engineering Department, National Institute of Technology, Warangal, Telengana, India. His research interests are focused on synthesis of hybrid nanomaterials, cavitation-based inorganic particle synthesis, sonochemical synthesis of nanolatex, process intensification, and microreactors for nanoparticles production. Dr. Sonawane has published more than 100 research papers in reputed journals, eight book chapters, and has six Indian patent applications.

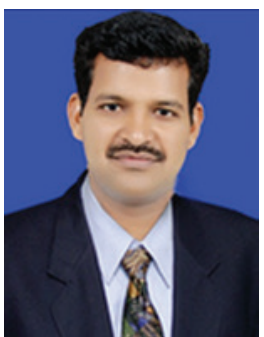

Bharat A. Bhanvase

Bharat A. Bhanvase is currently working as an associate professor at the Chemical Engineering Department, Laxminarayan Institute of Technology, RTM Nagpur University, Nagpur, Maharashtra, India. His research interests focus on wastewater treatment, cavitationbased nanomaterials and nanocomposites, process intensification, microfluidics, and nanofluids. He has 40 articles in international journals, four articles in national journals, and 19 book chapters to his credit. He is a recipient of the Young Scientist Award for Science and Engineering Research Board, New Delhi.

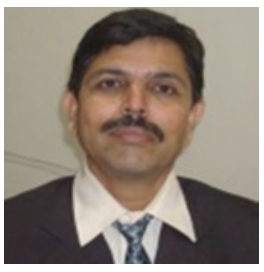

Ravindra D. Kulkarn

Ravindra D. Kulkarni is currently working as a professor and director at UICT, North Maharashtra University Jalgaon, Maharashtra, India. His professional areas of interest are: polymers, pigments, and paints; fats, oleochemicals, and surfactants; perfumes, waxes, and cosmetics; nanotechnology; reaction engineering and catalysis; tribology; and environmental engineering. Prof. Kulkarni has published more than 55 research papers in reputed journals, five book chapters, and has seven Indian patent applications. He has guided six PhD students. In 2014, the "Best Teacher Award" was bestowed on him by his excellency Shri Shankarnarayan, Governor, Maharashtra State. 


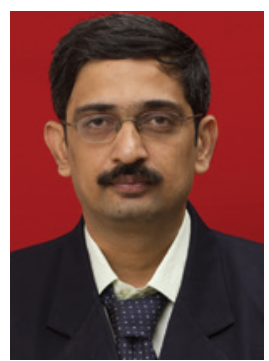

Parag R. Gogate

Parag R. Gogate has been a versatile chemical engineer with outstanding research work based on the use of alternate energy sources, wastewater treatment, and converting waste into value-added products. Dr. Gogate has contributed extensively to publishing in journals of high repute with 225 international journal publications along with over 7600 citations ( $h$-index of 47) as well as has written 15 chapters in edited books. Dr. Gogate has contributed extensively to the development of the profession by virtue of organization of refresher courses/seminars for participants from academic institutes/industries and also competitions for the student community. 